\title{
Malignant Peripheral Nervous System Neoplasm
}

National Cancer Institute

\section{Source}

National Cancer Institute. Malignant Peripheral Nervous System Neoplasm. NCI

Thesaurus. Code C4961.

Malignant growth of cells in the peripheral nervous system (PNS)or Autonomic Nervous System (ANS), without specification as to location 